\title{
Endothelin-1 during and after cardiopulmonary bypass: Association to graft sensitivity and postoperative recovery
}

\author{
Brian R. Bond, PhD \\ B. Hugh Dorman, MD, PhD \\ Mark J. Clair, MS, \\ C. Allyson Walker, BS \\ Mark L. Pinosky, MD \\ Scott T. Reeves, MD \\ Scott Walton, MD \\ John M. Kratz, MD \\ James L. Zellner, MD \\ A. Jackson Crumbley III, MD, PhD \\ Marlina M. Multani, BS \\ Francis G. Spinale, MD, PhD
}

From the Department of Cardiothoracic Surgery, Medical University of South Carolina, Charleston, SC.

Supported in part by National Institutes of Health grant HL-45024 (F.G.S.). C.A.W participated in these studies as a National Medical Fellowships Academic Fellow.

Received for publication April 17, 2000; revisions requested July 11, 2000; revisions received Dec 4, 2000; accepted for publication Jan 25, 2001.

Address for reprints: Francis G. Spinale, MD, PhD, Medical University of South Carolina, Strom Thurmond Research Building, 114 Doughty St, Suite 625, Charleston, SC 29403.

J Thorac Cardiovasc Surg 2001;122:358-64

Copyright (C) 2001 by The American Association for Thoracic Surgery

$0022-5223 / 2001 \$ 35.00+0 \quad \mathbf{1 2 / 1 / 1 1 4 9 3 6}$

doi:10.1067/mtc.2001.114936
Objective: Our objectives are 2-fold: (1) to serially measure the release of endothelin and graft-conduit endothelin sensitivity during and after coronary artery bypass grafting and (2) to define potential relationships of changes in endothelin levels to perioperative parameters.

Methods: Endothelin plasma content was measured in patients $(\mathrm{n}=105)$ undergoing bypass grafting from select vascular compartments before operations and at specific intervals up to 24 hours postoperatively. Endothelin sensitivity was determined in isolated internal thoracic artery segments.

Results: Systemic arterial and pulmonary arterial endothelin levels were increased by approximately $50 \%$ immediately after bypass grafting and increased by another $85 \%$ during the first 24 hours postoperatively. Endothelin levels were highest in patients with prolonged ventilatory requirements and extended stays in the intensive care unit $(10.2 \pm 0.8$ vs $13.2 \pm 1.1 \mathrm{fmol} / \mathrm{mL}, P=.02$, and $9.8 \pm 0.7$ vs $13.9 \pm 1.2$ $\mathrm{fmol} / \mathrm{mL}, P=.01$, respectively. Endothelin sensitivity of the internal thoracic artery was increased in patients requiring prolonged vasodilator support with nitroglycerin.

Conclusions: Systemic and pulmonary arterial endothelin levels remained increased for at least 24 hours postoperatively. Prolonged pharmacologic management and increased intensive care unit stay were associated with increased systemic endothelin release and heightened graft-conduit sensitivity to endothelin.

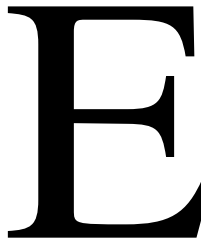

ndothelin-1 (ET-1) is a potent bioactive peptide that has been demonstrated to influence vascular resistance properties in the systemic, pulmonary, and coronary circulation. ${ }^{1,2}$ Moreover, exposure of myocardial preparations to ET-1 has been shown to influence contractile performance. ${ }^{3,4}$ Elevated plasma levels of ET-1 have been identified in a number of cardiovascular disease states, as well as during coronary artery bypass grafting (CABG) operations requiring cardiopulmonary bypass $(\mathrm{CPB}){ }^{5,6}$ Increased release of ET-1 may modulate systemic hemodynamics and myocardial contractility, which would have 
particular relevance in the post-CABG setting. ${ }^{7,8}$ However, the influences of ET- 1 on parameters of patient recovery after $\mathrm{CABG}$ remain unknown. Accordingly, the first objective of the present study was to examine potential relationships between the temporal profile of systemic arterial and pulmonary arterial ET-1 plasma levels to specific indices of recovery after CABG. The vasoconstrictive effects of ET-1 may have particular relevance to the vascular grafts used as CABG conduits. Therefore, the second objective of this study was to examine the relation between CABG conduit ET-1 sensitivity and postoperative parameters of recovery. This project tested the hypothesis that changes in ET-1 production and sensitivity were associated with alterations in specific perioperative parameters of recovery, which may contribute to a complex postoperative course of recovery.

\section{Materials and Methods \\ Patients}

After approval by the Human Subjects Review Committee of the Medical University of South Carolina, 105 consecutive patients undergoing elective CABG operations provided informed consent to participate in this study. Standard induction and maintenance of anesthesia was accomplished with a combination of sufentanil, midazolam, and isoflurane. Systemic heparinization was achieved with a heparin dose of $400 \mathrm{U} / \mathrm{kg}$. CPB was maintained at a cardiac index of 2.0 to $2.4 \mathrm{~L} \cdot \mathrm{min}^{-1} \cdot \mathrm{m}^{-2}$. Initial cardioplegic arrest was accomplished with antegrade administration of a $500-\mathrm{mL}$ solution of $\mathrm{D}_{5} 0.2 \mathrm{NaCl}$ containing $29 \mathrm{~mL}$ of tromethamine (THAM) buffer, $34 \mathrm{~mL}$ of adenosine citrate phosphate dextrose, and $60 \mathrm{mEq}$ of $\mathrm{KCl}\left(120 \mathrm{mEq} / \mathrm{L} \mathrm{K}^{+}\right)$. This was followed immediately by retrograde administration of $300 \mathrm{~mL}$ of the cardioplegic solution. Approximately every 20 minutes, cardioplegic arrest was maintained with a $400-$ to $700-\mathrm{mL}$ retrograde administration of the cardioplegic solution with a lower potassium concentration $(60 \mathrm{mEq} / \mathrm{L})$. At the termination of $\mathrm{CPB}$, heparin was neutralized with protamine at a 1:1 ratio. Discharge criteria from the intensive care unit (ICU) included a complete wean from all vasoactive and inotropic infusions, extubation without pulmonary support, and no evidence of major organ system failure.

Nitroglycerin infusion was administered postoperatively for systemic or pulmonary hypertension (defined as a $20 \%$ increase over preoperative levels) and ST segment elevation or depression of greater than $1 \mathrm{~mm}$. Epinephrine infusion was administered postoperatively to maintain a cardiac index of greater than $2.0 \mathrm{~L} \cdot \mathrm{min}^{-1} \cdot \mathrm{m}^{-2}$.

\section{Sample Time Points}

A 3-mL sample of blood was obtained from the radial artery before the induction of anesthesia to obtain a baseline systemic arterial ET-1 measurement. Samples were then collected from the radial artery and pulmonary artery at the following time points: just before $\mathrm{CPB}$, at aortic crossclamp removal, immediately after separation from $\mathrm{CPB}, 1 / 2$ hour after $\mathrm{CPB}$, and 6 and 24 hours postoperatively.

\section{ET-1 Measurement}

Whole blood for ET-1 measurement was collected in 3-mL tubes with ethylenediamine tetraacetic acid on ice. Plasma separated by centrifuging at $6000 \mathrm{~g}$ for 15 minutes at $4^{\circ} \mathrm{C}$ was transferred to polypropylene tubes and stored at $-80^{\circ} \mathrm{C}$. One milliliter of plasma was eluted over a cation exchange column (C-18 Sep-Pak; Waters Associates, Milford, Mass) and dried by means of vacuum centrifugation. The samples were reconstituted in $0.02 \mathrm{~mol} / \mathrm{L}$ borate buffer, and a high-sensitivity competitive ET-1 radioimmunoassay was performed (RPA 545; Amersham, Arlington Heights, Ill). Recovery from the extraction procedure was $75 \% \pm 5 \%$ on the basis of spiked plasma standards $(4-20 \mathrm{fmol} / \mathrm{mL})$. For repeated measurements of plasma samples and the inclusion of plasma samples with a known concentration of exogenous ET-1 added to the sample, the coefficient of variation was less than $12 \%$. By using an optimized extraction procedure, the sensitivity of this assay system was $0.0025 \mathrm{fmol} / \mathrm{mL}$. The within-assay precision for duplicate determinations was determined for 20 plasma samples, and the coefficient of variation was $4.4 \%$. The between-assay precision was assessed by repeated measurements of 20 plasma samples in successive radioimmunoassay procedures, and a coefficient of variation of $6.1 \%$ was determined.

\section{CABG Conduit Collection and Experimental Protocol}

Remnant segments of internal thoracic artery (ITA; $n=38$ ) and saphenous vein $(n=34)$ harvested for use as CABG grafts were collected from a subset of patients. After anastomosis, remaining grafts were placed into iced oxygenated Krebs-Henseleit buffer ( $4.6 \mathrm{mmol} / \mathrm{L} \mathrm{KCl}, 2.5 \mathrm{mmol} / \mathrm{L} \mathrm{CaCl}, 1.2 \mathrm{mmol} / \mathrm{L} \mathrm{KH}_{2} \mathrm{PO}_{4}, 118$ $\mathrm{mmol} / \mathrm{L} \mathrm{NaCl}, 2.5 \mathrm{mmol} / \mathrm{L} \mathrm{NaHCO}_{3}$, and $11 \mathrm{mmol} / \mathrm{L}$ glucose) and immediately transported to the laboratory. Vascular rings were prepared for tension measurements, as described by this laboratory previously. ${ }^{9}$ Developed tension from each ring was measured by using digital force transducers (Radnoti, Monrovia, Calif), and the digital signal was acquired for analysis by an acquisition system (BioBench; National Instruments, Austin, Tex). After a 1-hour equilibration period, each ring was exposed to increasing concentrations of ET-1 (0.1-100 nmol/L; Sigma, St Louis, Mo) at 20minute intervals. Steady-state vasoconstriction was achieved for each ET-1 concentration, and maximum developed tension was recorded. Developed tension for each vessel was reported as a percentage of maximal $\mathrm{KCl}$-induced $(80 \mathrm{mmol} / \mathrm{L}$ ) vasoconstriction to normalize for differences in mass and thickness between ring preparations. ${ }^{9}$ The concentration-tension curves were subjected to regression analysis by means of an exponential curve-fitting algorithm to compute the ET-1 concentration necessary to induce 50\% maximal vasoconstriction $\left(\mathrm{EC}_{50}\right)$. This $\mathrm{EC}_{50}$ computation was used as an index of vessel sensitivity for ET-1. Thus, lower $\mathrm{EC}_{50}$ values reflect an enhanced sensitivity of the vessel to the vasocontrictive effects of ET- 1 .

\section{Data Analysis}

Hemodynamic parameters and plasma ET-1 levels at each time point were first evaluated with a multi-way analysis of variance (ANOVA). If the ANOVA revealed significant differences, pairwise tests of individual group means were compared by Bonferroni adjusted probabilities. Categoric analyses of postoperative outcome 


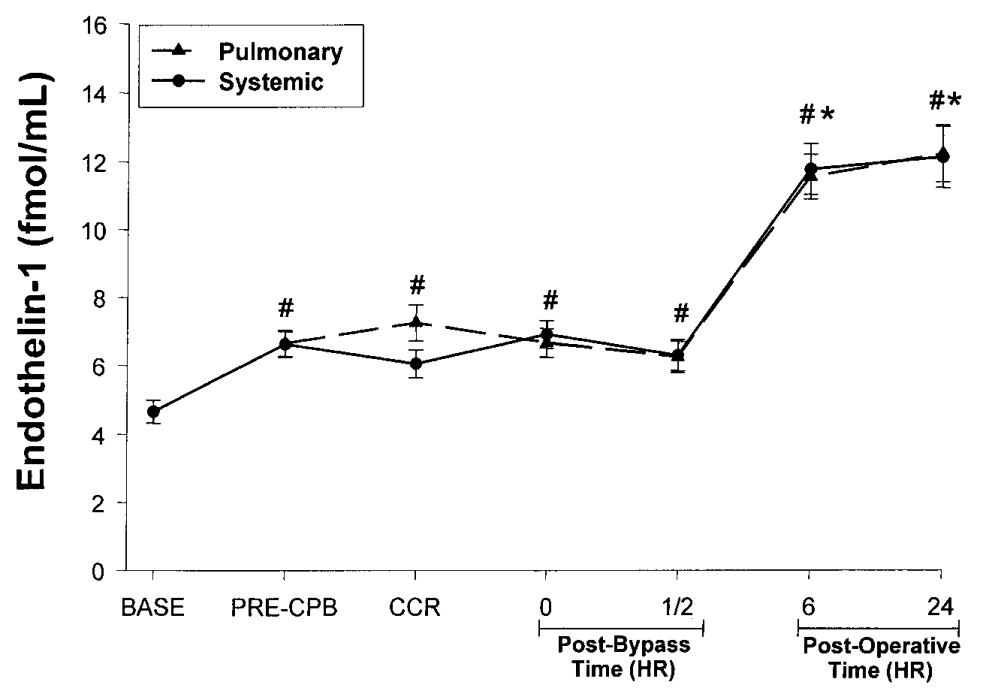

Figure 1. Systemic and pulmonary arterial plasma ET-1 levels during and after CPB in patients undergoing coronary revascularization. Systemic and pulmonary artery ET-1 levels were elevated during CPB compared with preoperative baseline values. Furthermore, ET-1 levels were further elevated at 6 and 24 hours postoperatively relative to values measured during the operative procedure. $B A S E$, Before the operation; PRE-CPB, immediately before CPB; CCR, aortic crossclamp removal; 0 , immediately after bypass cessation; 1/2, 30 minutes after bypass cessation; 6, 6 hours after the operation; 24, 24 hours after the operation $(\# P<.05$ versus BASE and $* P<.05$ versus PRE-CPB).

TABLE 1. Patient characteristics and clinical perioperative data

\begin{tabular}{|c|c|c|c|}
\hline & \multirow[b]{2}{*}{ Mean \pm SD } & \multicolumn{2}{|c|}{ Range } \\
\hline & & Lower & Upper \\
\hline Age (y) & $62 \pm 12$ & 33 & 87 \\
\hline No. of grafts & $3 \pm 1$ & 2 & 6 \\
\hline Bypass time (min) & $114 \pm 30$ & 50 & 185 \\
\hline Ventilation time (h) & $12 \pm 6$ & 1 & 25 \\
\hline ICU time (h) & $29 \pm 19$ & 15 & 108 \\
\hline Hospital stay (d) & $5 \pm 3$ & 2 & 33 \\
\hline
\end{tabular}

Data are presented as means \pm SD where shown $(n=105)$.

variables defined as ICU time, hospital stay, ventilator time, mean pulmonary artery pressure, and nitroglycerin treatment were placed into discrete intervals and analyzed with respect to ET-1 levels. These categories were chosen before data analysis on the basis of normal uncomplicated postoperative recovery periods for ICU time, hospital stay, and ventilator time for patients undergoing $\mathrm{CABG}$ operations in our institution (24 hours, 5 days, and 12 hours, respectively). By means of these cut points, individual comparisons of ET1 values were performed by an unpaired $t$ test. After the ET- 1 measurements, patients were grouped with respect to the presence or absence of diabetes. Systemic arterial plasma ET-1 levels were compared between the diabetic and nondiabetic groups by ANOVA and pairwise comparisons with Bonferroni adjusted probabilities. $\mathrm{EC}_{50}$ values for both ITA and saphenous vein were compared with these outcomes variables by means of the same approach. All statistical procedures were performed with the BMDP statistical software package (BMDP Statistical Software, Inc, Los Angeles, Calif). Results are presented as means \pm SEM unless indicated otherwise.

\section{Results}

Demographic and perioperative clinical descriptive data for the patients enrolled in this study are presented in Table 1. Changes in systemic hemodynamics after CPB were consistent with past reports and are summarized in Table $2 .{ }^{6}$ Heart rate, cardiac output, and mean arterial and pulmonary pressures were significantly elevated after CPB and postoperatively compared with values before CPB.

Systemic arterial and pulmonary arterial ET-1 levels were elevated by approximately $50 \%$ over baseline values throughout the surgical procedure (Figure 1). During the first 24 hours of the postoperative period, ET-1 levels were further increased in both vascular compartments. Systemic and pulmonary arterial ET-1 values at 6 and 24 hours postoperatively were increased $160 \%$ over baseline values and increased $85 \%$ relative to values obtained during the surgical procedure.

In the present study, $36 \%$ of the patients were diabetic. In the nondiabetic patients the baseline systemic arterial ET-1 values were $4.2 \pm 0.3 \mathrm{fmol} / \mathrm{mL}$ (95\% confidence intervals $[\mathrm{CI}], 3.5-4.8 \mathrm{fmol} / \mathrm{mL}$ ). In the diabetic patients baseline ET1 levels were higher than those in nondiabetic patients (5.4 $\pm 0.7 \mathrm{fmol} / \mathrm{mL} ; 95 \% \mathrm{CI}, 3.4-6.2 \mathrm{fmol} / \mathrm{mL})$, but this did not reach statistical significance $(P=.137)$. At 6 hours after $\mathrm{CPB}$, the systemic arterial ET-1 levels for the nondiabetic 
TABLE 2. Hemodynamic parameters before and after CPB

\begin{tabular}{|c|c|c|c|c|}
\hline & \multicolumn{2}{|c|}{ Post-CPB } & \multicolumn{2}{|c|}{ Postoperative } \\
\hline & Pre-CPB & $1 / 2 h$ & $6 \mathrm{~h}$ & $24 \mathrm{~h}$ \\
\hline Heart rate (beats/min) & $69 \pm 17$ & $90 \pm 19^{*}$ & $95 \pm 13^{*} \dagger$ & $85 \pm 12^{*} \dagger$ \\
\hline Cardiac output(L/min) & $4.8 \pm 1.5$ & $7.2 \pm 1.8^{*}$ & $6.1 \pm 1.6^{*} \dagger$ & $6.3 \pm 1.5^{*} \dagger$ \\
\hline Mean arterial pressure $(\mathrm{mm} \mathrm{Hg})$ & $69 \pm 14$ & $69 \pm 15$ & $76 \pm 12^{*} \dagger$ & $78 \pm 11^{*} \dagger$ \\
\hline Mean pulmonary pressure $(\mathrm{mm} \mathrm{Hg})$ & $14 \pm 6$ & $17 \pm 5^{*}$ & $21 \pm 5^{*} \dagger$ & $20 \pm 5^{*} \dagger$ \\
\hline PVR $\ddagger\left(\right.$ dyne $\left.\cdot \mathrm{s}^{-1} \cdot \mathrm{cm}^{-5}\right)$ & $83 \pm 91$ & $67 \pm 47$ & $88 \pm 123$ & $84 \pm 37 \dagger$ \\
\hline SVR (dyne $\cdot \mathrm{s}^{-1} \cdot \mathrm{cm}^{-5}$ ) & $1266 \pm 1082$ & $764 \pm 279^{*}$ & $919 \pm 365^{*} \dagger$ & $922 \pm 231^{*} \dagger$ \\
\hline
\end{tabular}

Data are presented as means $\pm \mathrm{SD}(\mathrm{n}=105)$. $P V R$, Pulmonary vascular resistance; $S V R$, systemic vascular resistance.

${ }^{*} P<.05$ versus pre-CPB.

$\dagger P<.05$ versus $1 / 2$ hour after CPB.

$\ddagger P=.16$ PVR $1 / 2$ hour versus 6 hours.

patient sample were $11.4 \pm 0.9 \mathrm{fmol} / \mathrm{mL}(95 \% \mathrm{CI}, 9.5-13.3$ $\mathrm{fmol} / \mathrm{mL})$. In the diabetic patients systemic arterial ET-1 levels at 6 hours after CPB were $11.9 \pm 1.1 \mathrm{fmol} / \mathrm{mL}(95 \%$ $\mathrm{CI}, 9.7-14.2 \mathrm{fmol} / \mathrm{mL}$ ) and were not different from nondiabetic patients $(P=.55)$.

Elevated ET-1 levels in the systemic arterial circulation 6 hours after the operation were observed in patients with prolonged ICU time, as defined by greater than 24 hours (Figure 2). In addition, systemic arterial ET-1 levels at 6 hours postoperatively were higher in patients with prolonged hospital stays of more than 5 days (Figure 2). Patients with elevated mean pulmonary artery pressures (defined as greater than $20 \mathrm{~mm} \mathrm{Hg}$ ) also displayed a significant increase in pulmonary artery ET levels at 6 hours postoperatively (Figure 3). Furthermore, prolonged ventilatory support of more than 12 hours was associated with higher pulmonary arterial ET-1 levels at 6 hours postoperatively (Figure 3).

CABG conduit sensitivity to ET-1 was determined by calculating the $\mathrm{EC}_{50}$ value from the ET-1 concentrationresponse curve generated from each isolated vessel (Figure 4). The average ET- $1 \mathrm{EC}_{50}$ value for all ITA vessels examined was $10.2 \pm 0.9 \mathrm{nmol} / \mathrm{L}$. $\chi^{2}$ Analysis of ITA ET-1 EC E0 $_{50}$ values and nitroglycerin treatment at 24 hours postoperatively revealed that only $10 \%(2 / 19)$ of patients with an $\mathrm{EC}_{50}$ of greater than $10 \mathrm{nmol} / \mathrm{L}$ required nitroglycerin treatment, whereas $42 \%(8 / 19)$ of patients with an $\mathrm{EC}_{50}$ of less than $10 \mathrm{nmol} / \mathrm{L}$ required nitroglycerin treatment $(P=.03)$. The mean saphenous vein $\mathrm{EC}_{50}$ value for exogenous ET-1 was significantly lower than the ITA value $(6.5 \pm 0.9$ vs 10.2 $\pm 0.9 \mathrm{nmol} / \mathrm{L}, P=.005)$.

\section{Discussion}

The bioactive peptide ET-1 has been shown to mediate vasoconstriction of the pulmonary and systemic circulation and influence myocardial contractility. ${ }^{2,10}$ Therefore, the overall goal of the present study was to identify the temporal pro- duction and concentration of ET-1 throughout the CABG perioperative period and to identify potential associations between ET-1 and specific postoperative parameters of recovery. The results of the present study demonstrated that pulmonary and systemic arterial ET-1 levels were persistently elevated in the perioperative period and that ET-1 sensitivity was clearly documented in conduits used for CABG. Moreover, the results of the present study provide evidence to suggest that higher ET-1 levels and greater ET-1 conduit sensitivity may be associated with specific indices of postoperative recovery.

Systemic and pulmonary arterial ET-1 levels were significantly elevated during the operation over baseline values in patients undergoing CABG, with a secondary increase occurring 24 hours into the postoperative period. These results are consistent with some previously published studies in which elevated ET-1 levels were detected during the perioperative period of cardiac operations. ${ }^{5,6}$ The cause for the increased perioperative ET-1 levels observed during CABG is probably multifactorial, including reduced ET-1 metabolism during CPB from reduced pulmonary vascular flow, damage to the endothelium during CPB caused by absent pulsatile perfusion, increased myocardial ET-1 production and release after reperfusion, increased stress from operations, and enhanced ET-1 biosynthesis caused by thromboxane release from activated platelets during CPB. ${ }^{11-14}$ Postoperative increases in ET-1 may be related to increased physiologic stress, as evidenced by peak levels of plasma catecholamines and stress hormones in the immediate postoperative period of CABG. ${ }^{15}$

Increased systemic arterial ET-1 levels in the early postoperative period would in turn result in increased perfusion of ET-1 within the myocardium. This would result in exposure of the coronary vasculature and myocardial cells to increased ET-1 levels, without the benefit of metabolism and clearance by the pulmonary vasculature. ${ }^{13,16}$ Moreover, several recent reports have shown a capacity for production 

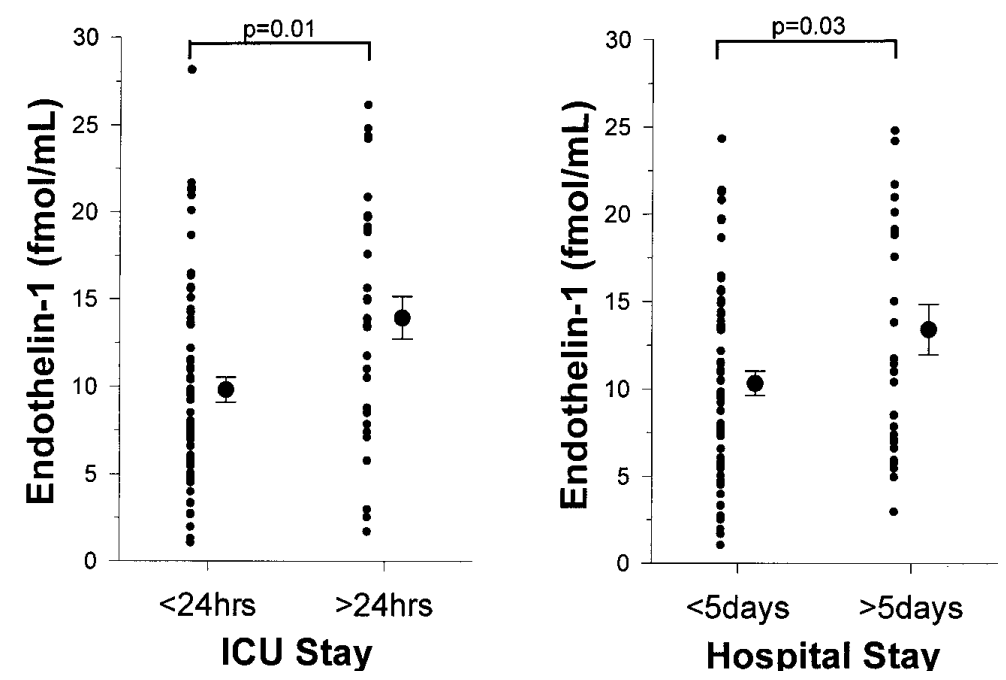

Figure 2. Systemic arterial ET-1 levels at 6 hours postoperatively were higher in patients with prolonged ICU time (defined as greater than 24 hours; left panel). Similarly, systemic ET-1 levels at 6 hours postoperatively were higher in patients with hospital stays of more than 5 days (right panel).
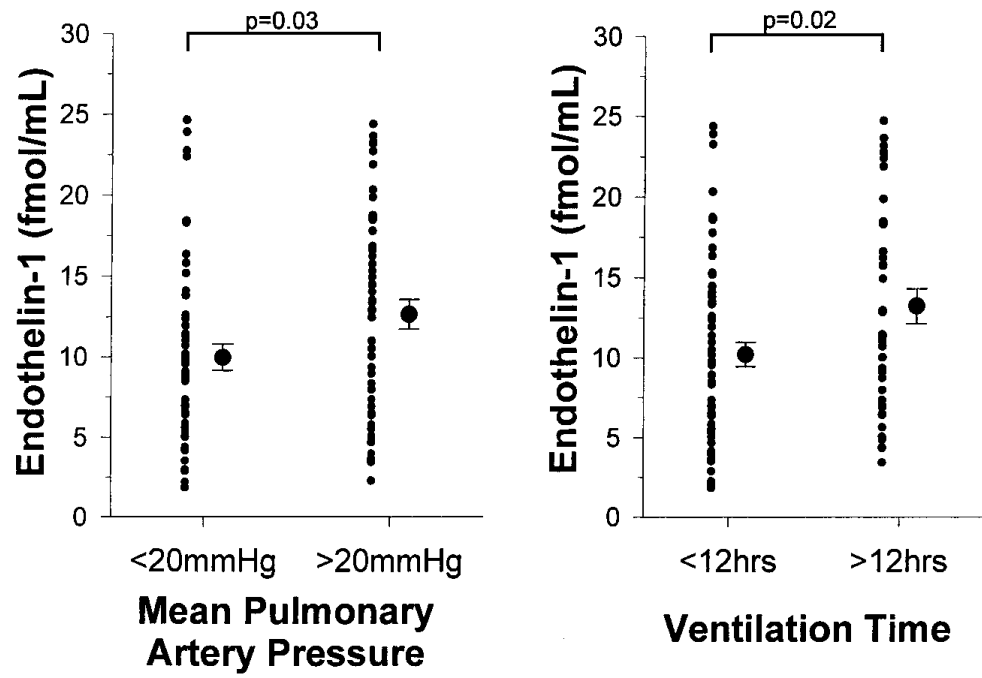

Figure 3. Pulmonary artery ET-1 levels at 6 hours postoperatively were higher in patients with elevated mean pulmonary artery pressure (defined as greater than $20 \mathrm{~mm} \mathrm{Hg}$; left panel). In addition, pulmonary artery ET-1 levels at 6 hours postoperatively were higher in patients requiring more than 12 hours of ventilatory support (right panel).

of ET-1 by the myocardium. ${ }^{14,17,18}$ By using microdialysis, a recent study by this laboratory has demonstrated that ET1 levels are compartmentalized within the myocardium and that local myocardial interstitial levels are much higher when compared with plasma levels. ${ }^{19}$ Thus, in the present study, the concentrations of ET-1 within the myocardium after CPB may be much higher than the documented plasma levels. ET-1 receptor antagonists have been shown to promote recovery of left ventricular function after hypothermic cardioplegic ischemia, ${ }^{7}$ and a reduction in isolated myocyte contractile function by ET-1 after cardioplegic arrest and rewarming has been demonstrated. ${ }^{20}$ However, in the absence of cardioplegic arrest, ET-1 has been shown to have a positive inotropic influence. ${ }^{21}$ The disparity in inotropic effect by ET-1 may be related to the observation that ET-1 can reduce $\left[\mathrm{Ca}^{2+}\right]_{\mathrm{i}}$ transients and activate $\mathrm{Na}^{+}-\mathrm{H}^{+}$exchange, resulting in changes in intracellular $\mathrm{pH}$ with alterations in myofilament sensitivity to $\mathrm{Ca}^{2+}$ and promotion of ischemic reperfusion injury. ${ }^{22-24}$ However, whether the increased ET1 levels that were observed in the present study directly 
influenced myocardial contractile function in the early postoperative period remain to be established.

Patients with elevated pulmonary artery ET-1 levels postoperatively displayed higher pulmonary artery pressures, which were associated with prolonged ventilatory support in the postoperative period. This agrees with the results of a prior study in pediatric patients undergoing repair of congenital heart disease, in which a significant association was observed between ET-1 levels after CPB and the maximum pulmonary/systemic arterial pressure ratio postoperatively. ${ }^{25}$ ET-1 has been demonstrated previously to cause sustained vasoconstriction of the pulmonary vasculature. ${ }^{8,10.18}$ Elevated pulmonary artery ET-1 levels may therefore negatively affect ventilation/perfusion ratios and pulmonary artery pressures in the early postoperative period. ${ }^{26,27}$

The present study reported robust ET-1-induced vasoconstriction of ITA and saphenous vein segments harvested for use as CABGs. Several prior studies examining the response of coronary conduits to ET-1 have shown potent vasoconstriction produced by ET-1, even in intact endothelium, with exaggerated responses in restrictive arteries and in conduits with atherosclerotic changes. ${ }^{28,29}$ Furthermore, threshold concentrations of ET-1 have been shown to specifically amplify ITA and coronary artery contractions induced by norepinephrine and serotonin. ${ }^{30,31}$ This study provides the first evidence to suggest that ET-1-mediated vasoconstriction of newly grafted ITA conduits may result in a prolonged requirement for the vasodilator nitroglycerin. Future studies examining postoperative ischemia and hypertension with an ET-1 antagonist would be useful to dissect out the contribution of ET-1 in postoperative ischemia and hypertension in patients undergoing CABG.

The increased ICU and hospital duration in patients with elevated postoperative ET-1 levels was not surprising, considering the broad spectrum of pathophysiologic changes associated with ET-1 after CABG. The present study described increased inotropic, ventilatory, and vasodilative requirements in certain subsets of patients with elevated ET1 in various vascular compartments after $\mathrm{CABG}$, all of which may contribute to prolonged patient recovery. First, the present study does not demonstrate that ET-1 is an independent contributory factor for the postoperative course after CABG. Other inflammatory mediators that are typically generated during CPB may affect patient recovery, such as leukotrienes, bradykinin, and complement, which were not considered. Second, the sample size of the present study was limited and therefore prevented a stasticially robust analysis of the direct relationship between ET-1 and postoperative outcomes. Patients selected for these studies were those undergoing elective $\mathrm{CABG}$ procedures, and therefore confounding factors, such as comorbidities, and other preoperative factors were not considered in the study design. For example, alterations in vascular sensitivity to ET-1 have

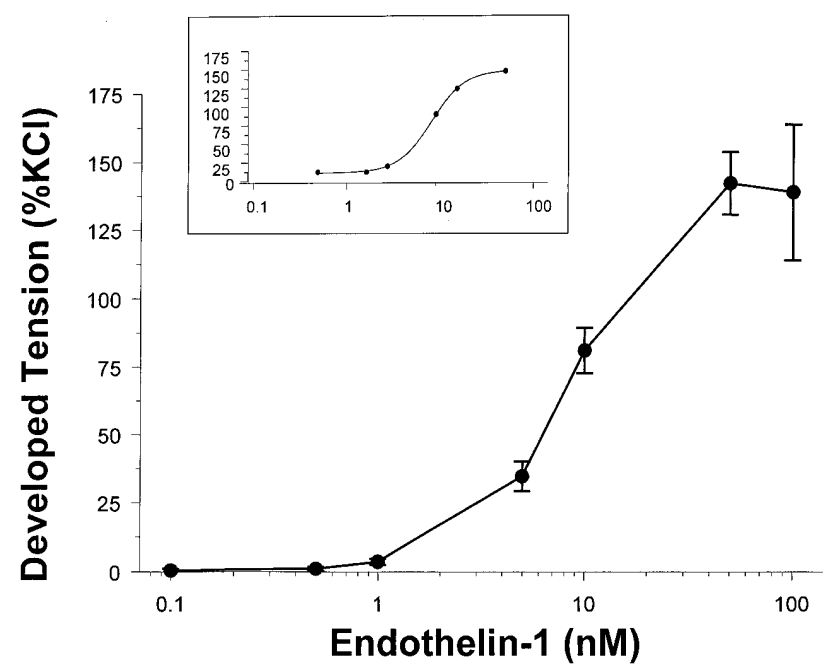

Figure 4. ET-1 tension-response curve generated from ITA samples ( $n=38$ ) exposed to increasing concentrations of ET-1 (0.1-100 $\mathrm{nmol} / \mathrm{L})$. These curves allowed for the computation of the concentration of ET-1 necessary to induce $\mathrm{EC}_{50}(10.2 \pm 0.9 \mathrm{nmol} / \mathrm{L})$. Inset shows a representative tension-concentration curve for an individual ITA segment.

been reported in models of diabetes. ${ }^{32}$ The present study was not designed to differentiate the relationship of changes in ET-1 to diabetes in the postoperative period. Thus, the increased ET-1 levels that were observed in a selected group of patients with a more complex postoperative course may represent ET-1 release as a compensatory response to other underlying mechanisms. Nevertheless, the present study demonstrated that the potent bioactive peptide ET-1 is increased in various vascular compartments after CABG and $\mathrm{CPB}$, which in turn may contribute to a more complex postoperative course.

\section{References}

1. Kiowski W, Sutsch G, Hunziker P, et al. Evidence for endothelin-1mediated vasoconstriction in severe chronic heart failure. Lancet. 1995;346:732-6.

2. Wenzel RR, Fleisch M, Shaw S, et al. Hemodynamic and coronary effects of the endothelin antagonist bosentan in patients with coronary artery disease. Circulation. 1998;98:2235-40.

3. Thomas PB, Liu EC, Webb ML, et al. Exogenous effects and endogenous production of endothelin in cardiac myocytes: potential significance in heart failure. Am J Physiol. 1996;271(Suppl):H2629-37.

4. Spinale FG, Walker JD, Mukherjee R, Iannini JP, Keever AT, Gallagher KP. Concomitant endothelin receptor subtype A blockade during the progression of congestive heart failure in rabbits has direct and beneficial effects on left ventricular and myocyte function. Circulation. 1997;95:1918-29.

5. Matheis G, Haak T, Beyersdorf F, Baretti R, Polywka C, Winkelmann BR. Circulating endothelin in patients undergoing coronary artery bypass grafting. Eur J Cardiothorac Surg. 1995;9:269-74.

6. Knothe $\mathrm{CH}$, Boldt J, Zickmann B, Ballesteros M, Dapper F, Hempelmann G. Endothelin plasma levels in old and young patients 
during open heart surgery: correlations to cardiopulmonary and endocrinology parameters. J Cardiovasc Pharmacol. 1992;20:66470.

7. Hiramatsu T, Forbess J, Miura T, Roth SJ, Cioffi MA, Mayer JE. Effects of endothelin-1 and endothelin-A receptor antagonist on recovery after hypothermic cardioplegic ischemia in neonatal lamb hearts. Circulation. 1995;92(Suppl):II-400-4

8. Petrossian E, Parry AJ, Reddy VM, et al. Endothelin receptor blockade prevents the rise in pulmonary vascular resistance after cardiopulmonary bypass in lambs with increased pulmonary blood flow. $J$ Thorac Cardiovasc Surg. 1999;117:314-23.

9. Bond BR, Zellner JL, Dorman BH, et al. Differential effects of calcium channel antagonists in the amelioration of radial artery vasospasm. Ann Thorac Surg. 2000;69:1035-40.

10. Holm P, Liska J, Clozel M, Franco-Cereceda A. The endothelin antagonist bosentan: hemodynamic effects during normoxia and hypoxic pulmonary hypertension in pigs. $J$ Thorac Cardiovasc Surg. 1996;112:890-7.

11. Milner P, Bodin P, Loesch A, Burnstock G. Rapid release of endothelin and ATP from isolated endothelial cells exposed to increased flow. Biochem Biophys Res Commun. 1990;170:649-56.

12. Ohlstein EH, Storer BL, Butcher JA, et al. Platelets stimulate expression of endothelin mRNA and endothelin biosynthesis in cultured endothelial cells. Circ Res. 1991;69:832-41.

13. DeNucci G, Thomas R, D'Orleans-Juite P, et al. Pressor effects of circulating endothelin are limited by its removal in the pulmonary circulation and by the release of prostacyclin and endothelium-derived relaxing factor. Proc Natl Acad Sci U S A. 1988;85:9797-800.

14. Pearson PJ, Lin P, Schaff HU. Production of endothelium-derived contracting factor is enhanced after coronary reperfusion. Ann Thorac Surg. 1991;51:788-93.

15. Reves J, Karp R, Buttner E, et al. Neuronal and adrenomedullary catecholamine release in response to cardiopulmonary bypass in man. Circulation. 1982;66:49-55.

16. Dupuis J, Stewart DJ, Cernacek P, et al. Human pulmonary circulation is an important site for both clearance and production of endothelin-1. Circulation. 1996;94:1578-84.

17. Wang QD, Hemsen A, Li XS, Lundberg JM, Uriuda Y, Pernow J. Local overflow and enhanced tissue content of endothelin following myocardial ischaemia and reperfusion in the pig: modulation by Larginine. Cardiovasc Res. 1995;29:44-9.

18. Velasco CE, Turner M, Inagami T, et al. Reperfusion enhances the local release of endothelin after regional myocardial ischemia. Am Heart J. 1994;128:441-51.

19. Ergul A, Walker CA, Goldberg A, et al. Endothelin-1 in the myocar- dial interstitium in heart failure: relation to myocyte ECE activity and expression. Am J Physiol. 2000;278:H2050-6.

20. Dorman BH, New BR, Bond BR, et al. Myocyte endothelin exposure during cardioplegic arrest exacerbates contractile dysfunction following reperfusion. Anesth Analg. 2000;90:1080-5.

21. Watanabe T, Kusumoto K, Kitayoshi T, Shimamoto N. Positive inotropic and vasoconstrictive effects of endothelin-1 in in vivo and in vitro experiments: characteristics and the role of L-type calcium channels. J Cardiovasc Pharmacol. 1989;13:5108-11.

22. Delpech N, Soustre H, Potreau D. Endothelin-1 inhibits L-type $\mathrm{Ca}^{2+}$ current enhanced by isoprenaline in rat atrial myocytes. $J$ Cardiovasc Pharmacol. 1997;29:136-43.

23. Khandoudi N, Ho J, Karmazyn M. Role of $\mathrm{Na}^{+}-\mathrm{H}^{+}$exchange in mediating effects of endothelin-1 on normal and ischemic/reperfused hearts. Circ Res. 1994;75:369-78.

24. Kohmoto O, Ikenouchi H, Hirata Y, Momomura S, Serizawa T, Barry WH. Variable effects of endothelin- 1 on $\left[\mathrm{Ca}^{2+}\right]_{\mathrm{i}}$ transients, $\mathrm{pH}_{\mathrm{i}}$ and contraction in ventricular myocytes. Am J Physiol. 1993;265:H793800 .

25. Komai H, Adatia IT, Elliott MJ, de Leval MR, Haworth S. Increased plasma levels of endothelin-1 after cardiopulmonary bypass in patients with pulmonary hypertension and congenital heart disease. $J$ Thorac Cardiovasc Surg. 1993;106:473-8.

26. Zhu ZG, Wang MS, Jiang ZB, et al. The dynamic change of plasma endothelin-1 during the perioperative period in patients with rheumatic valvular disease and secondary pulmonary hypertension. $J$ Thorac Cardiovasc Surg. 1994;108:960-8.

27. West JB. Blood flow to the lung and gas exchange. Anesthesiology. 1974;124:41-6.

28. Davies MG, Klyachkin ML, Kim JH, Hagen P. Endothelin and vein bypass grafts in experimental atherosclerosis. J Cardiovasc Pharmacol. 1993;22:S348-51.

29. Tippins JR, Antoniw JW, Maseri A. Endothelin-1 is a potent constrictor in conductive and resistive coronary arteries. J Cardiovasc Pharmacol. 1989;131:S177-9.

30. Lin P, Pearson PJ, Schapp HV. Endothelium-dependent contraction and relaxation of the human and canine internal mammary artery: studies on bypass graft vasospasm. Surgery. 1991;110:127-35.

31. Yang Z, Richard V, von Segesser L, et al. Threshold concentrations of endothelin-1 potentiate contractions to norepinephrine and serotonin in human arteries. Circulation. 1990;82:188-95.

32. Hopfner RL, McNeill JR, Gopalakrishnan V. Plasma endothelin levels and vascular responses at different temporal stages of streptozotocin diabetes. Eur J Pharmacol. 1999;374:221-7.

The Journal of Thoracic and Cardiovascular Surgery gives you two tables of contents.

The condensed table of contents tells you at a glance what topics and authors are presented each month. The expanded table of contents gives you a brief abstract of each article. You select only those articles of most interest to you for further reading. 